\title{
Complutum
}

ISSN: 1131-6993

\section{El poblamiento de La Gavia en el contexto del final de la Edad del Hierro en la Comunidad de Madrid. Actuaciones arqueológicas en La Gavia III}

\author{
Dionisio Urbina Martínez'; Jorge Morín de Pablos²
}

Recibido: 3 de enero de 2017 / Aceptado: 30 de julio de 2017

Resumen. Presentamos un avance de las excavaciones arqueológicas realizadas en el asentamiento La Gavia III. Este lugar estuvo habitado desde finales del siglo III-inicios del II a mediados del siglo I a.C. Se localiza en la vega del río Manzanares a los pies del cerro de La Gavia, en donde se excavó un recinto amurallado de la misma época en 1999. Los hallazgos aportan un modelo poco conocido sobre la transformación del espacio en torno al poblado fortificado en los últimos siglos anteriores a nuestra Era.

Palabras clave: Arqueología protohistórica; Segunda Edad del Hierro Tardía; recintos fortificados; romanización; valle del Manzanares; Madrid.

[en] The settlement of La Gavia in the context of the end of the Iron Age in the Community of Madrid. Archaeological activities in La Gavia III

\begin{abstract}
We present a preview of the archaeological excavations in the settlement of La Gavia III. This place was inhabited from the late third-early second century to the mid-first century BC It is located in the valley of the Manzanares river at the foot of the hill of La Gavia, where a fortress from the same period was excavated in 1999. The findings provide a little known model on space trasnformación around the fortified settlement in the last centuries before our Era.
\end{abstract}

Keywords: Protohistoric Archaeology, Late Second Iron Age, Walled Settlements, Romanization, Manzanares Valley, Madrid.

Sumario. 1. Introducción. 2. Estructuras documentadas. 3. Materiales arqueológicos. Producciones cerámicas. 4. Materiales arqueológicos. Metales. 5. Materiales arqueológicos. Ecofactos. 6. Cronología. 7. Conclusiones. La Gavia III y el poblamiento de La Gavia en el contexto del final de la Edad del Hierro en la Comunidad de Madrid.

Cómo citar: Urbina Martínez, D.; Morín de Pablos, J. (2017): El poblamiento de La Gavia en el contexto del final de la Edad del Hierro en la Comunidad de Madrid. Actuaciones arqueológicas en La Gavia III. Complutum, 28(1): $185-202$.

\section{Introducción}

A finales del año 2010 y comienzos de 2011 se realizó una actuación arqueológica en el entorno del Cerro de La Gavia, en virtud de los trabajos de evaluación de la afección a los restos arqueológicos de la obra civil de construcción de plataforma para incremento de capacidad en las líneas de Alta Velocidad entre Madrid y
Levante (tramo Atocha-Torrejón de Velasco), realizada por la empresa Aldesa Construcciones S.A. Las actuaciones arqueológicas se llevaron a cabo en tres sectores diferenciados en una línea paralela al curso del río Manzanares de unos 23-25m de ancho.

En esta zona se vienen realizando hallazgos arqueológicos desde que 1919 suscitara el interés de prehistoriadores como Hugo Ober-

\footnotetext{
E-mail: d.urbina@ayahoo.com

Audema S.A.

E-mail: jmorin@audema.com
} 


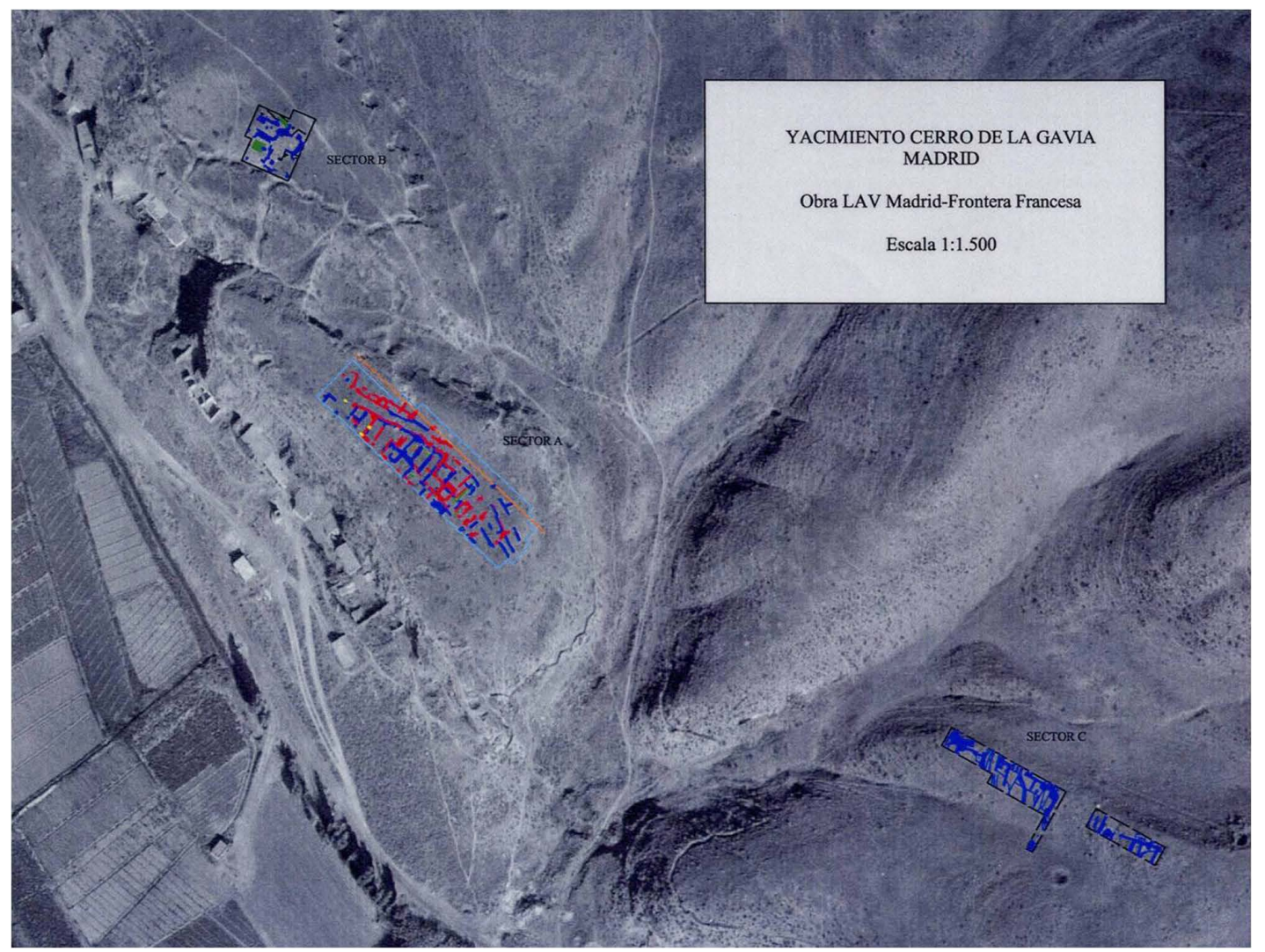

Figura 1. Fotografía aérea o plano general del lugar de realización de los trabajos con planimetría de los 4 sectores excavados.

maier, Paul Wernert y José Pérez de Barradas (Pérez de Barradas 1924: 16-20). Las investigaciones sobre el Paleolítico irán poniendo de relieve la importancia de los vestigios de otras épocas y así en los años 30 ya se menciona la presencia de cerámicas pintadas, estampillas y romanas (Fuidio 1934: 14), y el yacimiento aparece como un ejemplo de los "castros" de la provincia de Madrid (Pérez de Barradas 1935: 228). En 1980 la Edad del Hierro irá cobrando protagonismo entre las investigaciones de la Prehistoria madrileña, y en esa década aparecen estudios sobre las colecciones cerámicas que se habían venido recogiendo en los años anteriores en el cerro (Priego 1980: 93-112). La Gavia será una referencia constante desde entonces en las publicaciones sobre la Edad del Hierro (Blasco et al. 1980; Valiente 1987: 121-133; Blasco y Barrio 1991), hasta que finalmente en 1999-2000 se realice una excavación arqueológica en extensión (Quero et al. 2005; Morín y Urbina 2013).

Estas excavaciones sirvieron para definir el yacimiento como uno de los recintos amurallados que son relativamente frecuen- tes entre los escarpes yesíferos de los valles fluviales del centro peninsular (Urbina 2000 y 2012). Los materiales descubiertos permitieron establecer una cronología desde mediados del siglo IV a.C. hasta prácticamente el cambio de Era. Uno de los aspectos más novedosos que entonces se puso de manifiesto, junto a la constatación de la pervivencia del hábitat en un recinto amurallado hasta fechas tan tardías, será la existencia de dos recintos habitados fuera de los límites del poblado, uno de ellos extramuros (recinto B) y otro alejado ya casi $1 \mathrm{~km}$ del cerro (recinto C). Este hecho ponía de relieve que el hábitat en estos momentos era mucho más complejo de lo que se venía suponiendo y que desde luego no se limitaba estrictamente al recinto defendido de cerros y espolones (Morín et al. 2007). Las actuaciones en la vega del río Manzanares (Gavia III) que aquí damos a conocer de forma resumida, abundan en la complejidad de estos hábitats, al tiempo que nos permiten observar la evolución de un antiguo enclave indígena ya bajo el influjo de Roma en el período republicano. 
El poblado del cerro de La Gavia se levanta sobre uno de los espolones yesíferos de la margen izquierda del valle del río Manzanares, que en esta zona pueden alcanzar una altura de hasta $40 \mathrm{~m}$ sobre las tierras de la vega. En los últimos años, como fruto del crecimiento de la ciudad de Madrid, el cerro y sus alrededores se ha visto afectado por diversas obras, entre ellas la construcción de las líneas de ferrocarril de los trenes de Alta Velocidad Madrid-Barcelona y Madrid-Sevilla y la carretera M-45, que han alterado drásticamente su morfología original. La actuación arqueológica de La Gavia III se realizó entre el cauce de río y los escarpes yesíferos separados por una franja de terrenos aluviales de $150 \mathrm{~m}$ de ancho. La traza de la obra discurre paralela al cauce de agua, prácticamente a los pies del cerro de La Gavia. La superficie total excavada es algo inferior a los $600 \times 23 \mathrm{~m}$ y sólo representa muy parcialmente el espacio que debió ocupar este asentamiento, que podemos considerar como la misma unidad de población que la situada en la cima del cerro.

\section{Estructuras documentadas}

El área arqueológica denominada Gavia III comprende tres sectores diferenciados y separados entre ellos: Sector I.- Desde el P.K. $107+080$ al 107+200, Sector II.- Desde el P.K. $107+340$ al $107+420$ y Sector III.- Desde el P.K. $107+480$ al $107+680$. Los restos más relevantes de la Edad del Hierro aparecieron en el Sector II, que se encuentra casi bajo el viaducto de la M-45. Por lo que respecta al Sector I, se localizaron diversas estructuras negativas correspondientes a una ocupación de época islámica (siglos IX-X), entre las que aparecieron algunos materiales cerámicos de la Segunda Edad del Hierro. En el Sector III se documentan de nuevo un aserie de estructuras negativas con materiales islámicos asociados, entre los que se hallan algunos fragmentos de cocina y sigillatas de finales del siglo I d.C.

De entre los restos hallados en La Gavia III destacan, como decíamos, los hallados en el Sector II correspondientes a la Segunda Edad del Hierro. Se trata de una barriada que ha llegado a nosotros parcialmente conservada, ya que se halla muy afectada por las labores agrícolas, lo cual dificulta su correcta interpretación. A diferencia del espacio urbano del poblado hallado en la cima del cerro, en la vega se documentan estancias que parecen conformar unidades distintas a las de una vivienda, con grandes espacios vacíos y estancias de gran tamaño, o en todo caso viviendas de morfología muy diferente a las localizadas dentro del recinto amurallado.

En el extremo meridional y a pesar de la fuerte alteración que han sufrido algunas de las estructuras, se puede apreciar la existencia de un gran espacio delimitado por un muro de mayor grosor, transversal a la traza de la obra en su extremo septentrional y otro al sur, al que se adosan diversas estructuras (ámbito 5). El espacio así acotado tiene un ancho de unos $15 \mathrm{~m}$ y una longitud desconocida por extenderse más allá de la traza de la obra. Dentro de él, las distintas habitaciones parecen distribuirse en torno a un espacio cuadrado de unos $7 \times 7 \mathrm{~m}$ (habitación 5), que parece funcionar a modo de patio o distribuidor en torno al cual se alinean una serie de estancias cuadradas de $4 \times 4 \mathrm{~m}$ y otras rectangulares de unos $3,5 \times 6 \mathrm{~m}$. En concreto, en la parte septentrional en torno al patio, se dispone un estancia cuadrada en el centro y a sus lados dos rectangulares, en cada de las cuales se conservan restos de un hogar, en un caso en posición central y con fragmentos de cerámica como solera y en el otro en una de sus esquinas, mientras que la estancia cuadrada aparece un receptáculo delimitado por piedras en una de sus esquinas exteriores y en el muro divisorio con el supuesto distribuidor aparece amortizada una meta de molino doméstico de cereal.

Todo el ala Este se encuentra muy alterada por lo que la ausencia de muros delimitadores podría deberse a posteriores efectos antrópicos, o en caso contrario podríamos estar ante la entrada al conjunto.

En la parte occidental apenas se conservaban estructuras salvo la esquina noreste de la misma. Además de un hoyo con relleno entre el que se documentan varios fragmentos de cerámicas islámicas, hay que destacar la presencia de algunas grandes lajas de caliza que parecen los restos de un pavimento que debió existir por toda la estancia. Es estas una característica exclusiva de este ámbito, ya que en el resto del área excavada los pavimentos suelen estar constituidos por una capa de tierra apisonada. En la parte en donde no se conserva o no existió este pavimento, aparecen los restos de una oquedad rellena con abundante grano quemado, así como numerosos fragmentos de adobes o tierra igualmente quemada. Más se- 


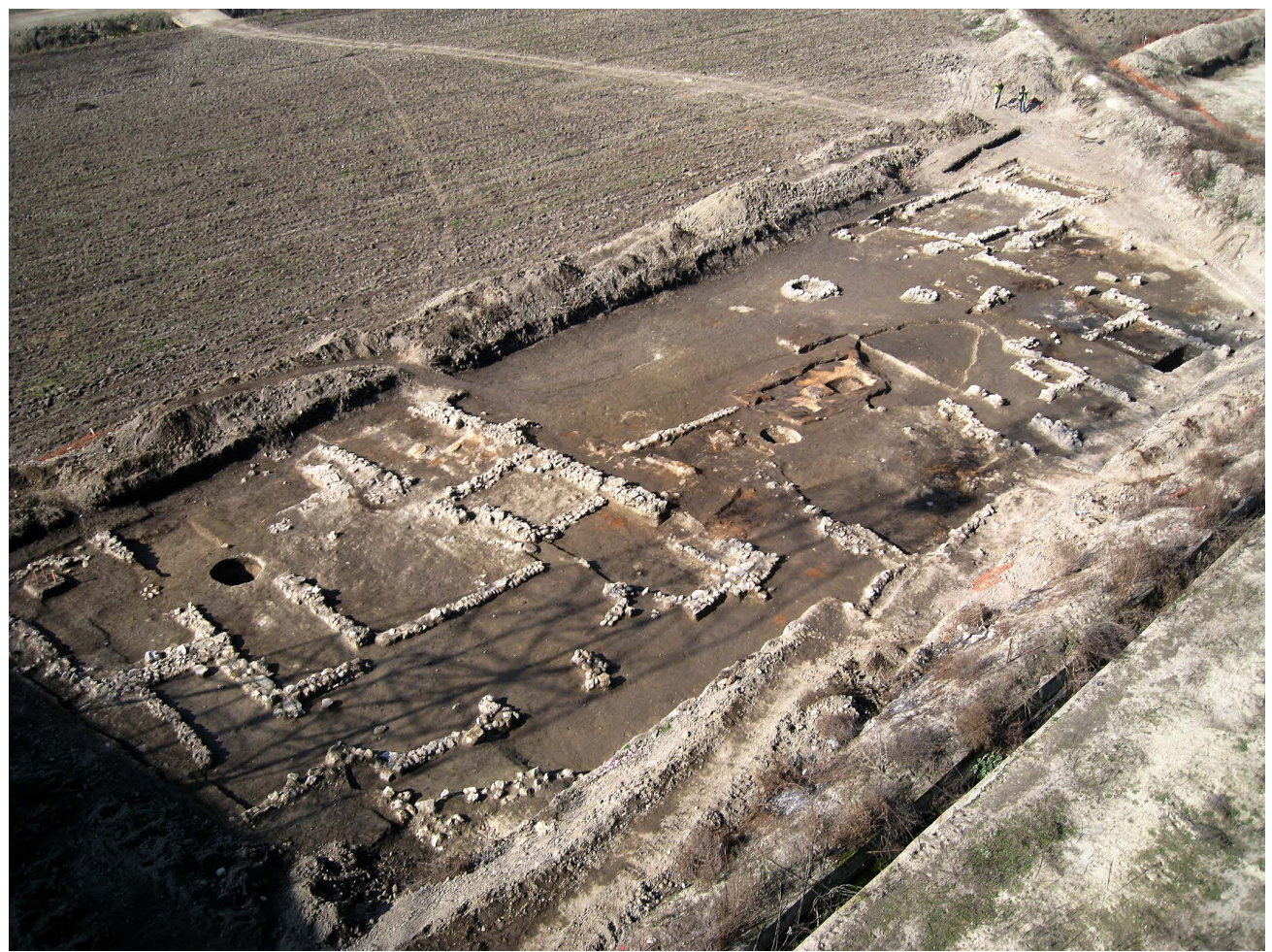

Figura 2. Fotografía aérea de los restos encontrados en el sector II.

millas, adobes quemados y trozos de carbones se esparcen en torno los restos de lo que debió ser algún tipo de silo con alzado de adobes. Junto a ellos se constata la presencia de uno de los mayores conjuntos cerámicos encontrados en el yacimiento, aunque todos ellos muy fragmentados y afectados por el fuego. Estos fragmentos corresponden a pequeños recipientes de servicio como cuencos y caliciformes pintados, por lo que no parece que nos encontremos en un área exclusiva de almacenamiento, sino cercana al lugar de transformación del grano en harina y el servicio de los alimentos o sala de tratamiento de cereal.

Entre los restos hallados en el distribuidor o estancia central merece la pena destacar la presencia de una fíbula de bronce de tipo omega, con sección romboidal y remate cilíndrico, del tipo 35.1a de R. Erice (1995: lám. 67-71) que la fecha en el siglo I a.C., o de anillo abierto tipo B.2 de González Zamora (1999: 402 y ss.) que las ubica a mediados de dicha centuria.

Al norte del muro que delimita este conjunto de estructuras, se abre un espacio vacío dominado por una estructura rectangular de adobes muy afectada por el fuego, lo que ha permitido su conservación. En el lado Norte se conservan los restos de algunos zócalos de piedra entre los que son notorias las manchas negruzcas con acúmulos de carboncillos y los restos ocres de tierra quemada.

En medio de este espacio vacío se levanta un edificio de recias paredes de tierra totalmente rubefactadas por efecto del incendio que afectó a toda la zona. Tiene unas medidas aproximadas de $4 \mathrm{~m}$ de longitud y $2 \mathrm{~m}$ de anchura y presenta un pilar central de forma cuadrangular. La entrada se halla hacia el sur, en una de las paredes cortas, que tiene un grosor de hasta $80 \mathrm{~cm}$. El conjunto de la estancia es robusto, con poco espacio interior en relación al grueso de sus paredes. Toda ella se encuentra muy afectada por un fuego que, a juzgar por el color de la tierra y su grado de compactación, debió alcanzar muy altas temperaturas. Podríamos estar ante algún tipo de horno aunque no hay que descartar otros usos.

Cortando un poco el pilar central de este edificio aparece una cavidad ovalada practicada sin duda cuando se encontraba ya amortizado. Dentro de ella se halló la parte superior de un molino rotatorio de mano, de granito. El agujero central es muy grande, de unos $12 \mathrm{~cm}$ de diámetro, así como toda la pieza que alcanza los $50 \mathrm{~cm}$ de diámetro y que a su vez es bastante plana, con paralelos en los molinos 


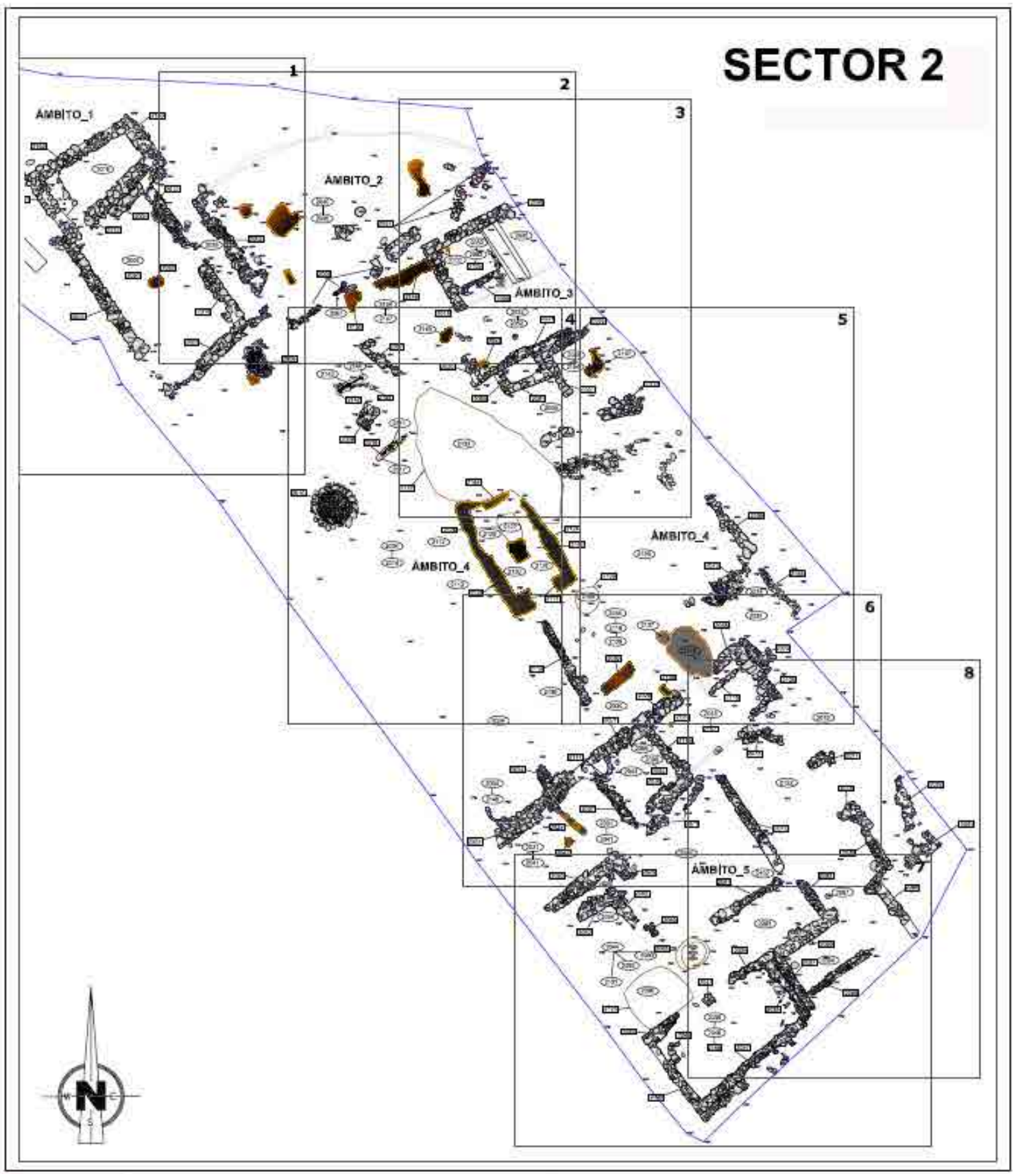

Figura 3. Planimetría del Sector II.

ibéricos del levante peninsular más que en los posteriores romanos (Alonso 1999). Se debió depositar en el agujero una vez rota.

Al noroeste del edificio de quemado se conservan los restos de 3 estructuras circulares formadas por una corona de piedras, similares a las de los zócalos de los muros, con un diámetro interior en torno a $1,1 \mathrm{~m}$, rellenas de pequeños cantos y guijarros entre tierra apisonada. En la mejor conservada este relleno presenta una potencia de $20 \mathrm{~cm}$ de grosor que es el mismo de la hilada de piedras del anillo exterior. Llama la atención la ausencia de indicios de fuego a simple vista, a pesar de que la forma de la estructuras invita a interpretarlas como hogares o bases de hornos, y de hecho una estructura idéntica hallada dentro de un estancia fue interpretada como horno de pan en el poblado de alicantino de El Oral (Abad y Sal 1993: lám. XIII.2) 


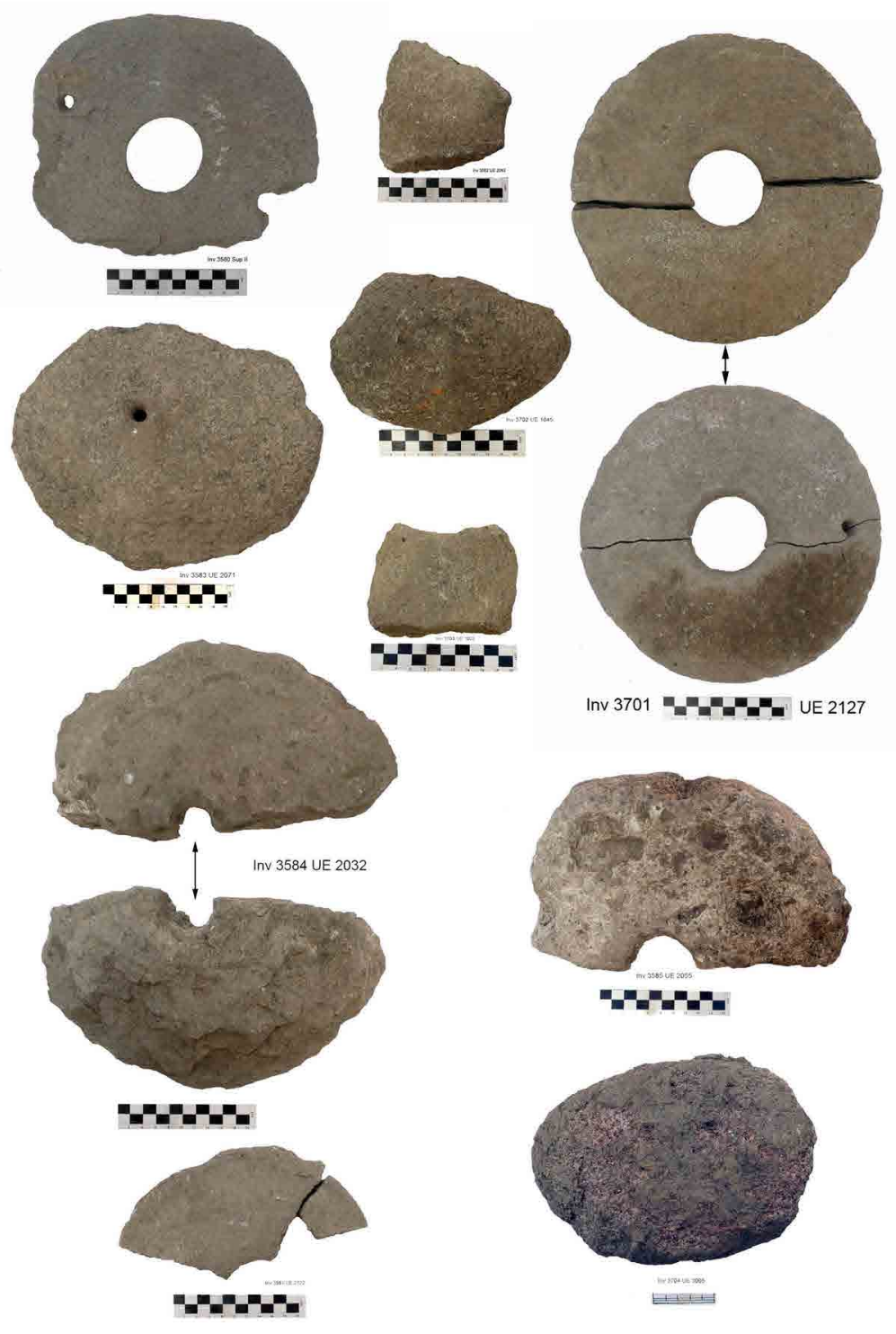

Figura 4. Piedras de diferentes molinos halladas en La- Gavia III

Todos este espacio fue amortizado y cubierto por una capa de tierra entre la que se encontraron numerosos fragmentos cerámicos que corresponden al momento final de la ocupación de la Edad del Hierro, aunque las estructuras con ellos relacionadas han desaparecido por completo. Ello dificulta más, si cabe, la interpretación de las estructuras circulares y el edificio quemado. La presencia de molinos y el depósito de granos antes comentado, podrían relacionar los restos con actividades de procesamiento del cereal, y así tal vez las estructuras circulares podrían ser la base de unos depósitos de cereal a modo de graneros familiares, aunque estructuras similares (Gast y Sigaut 1985). En algún otro yacimiento de la Comunidad de Madrid se encontraron espacios con fuertes evidencias de fuego, granos quemados, molinos rotatorios y machones y fragmento de paredes de adobe o tapial quemados. Hablamos del yacimiento de Fuente de la Mora, en Leganés (Vega et al. 2007). Parece como si no fuera demasiado extraño encontrar ambientes relacionados con el tratamiento del cereal afectados por el fuego, no sabemos si por el hecho de que los propios granos fueran un material propicio a quemarse, o bien porque los procesos a los que era comúnmente sometido aumentaban el peligro de incendio. Esos procesos se relacionan con el tostado de los 


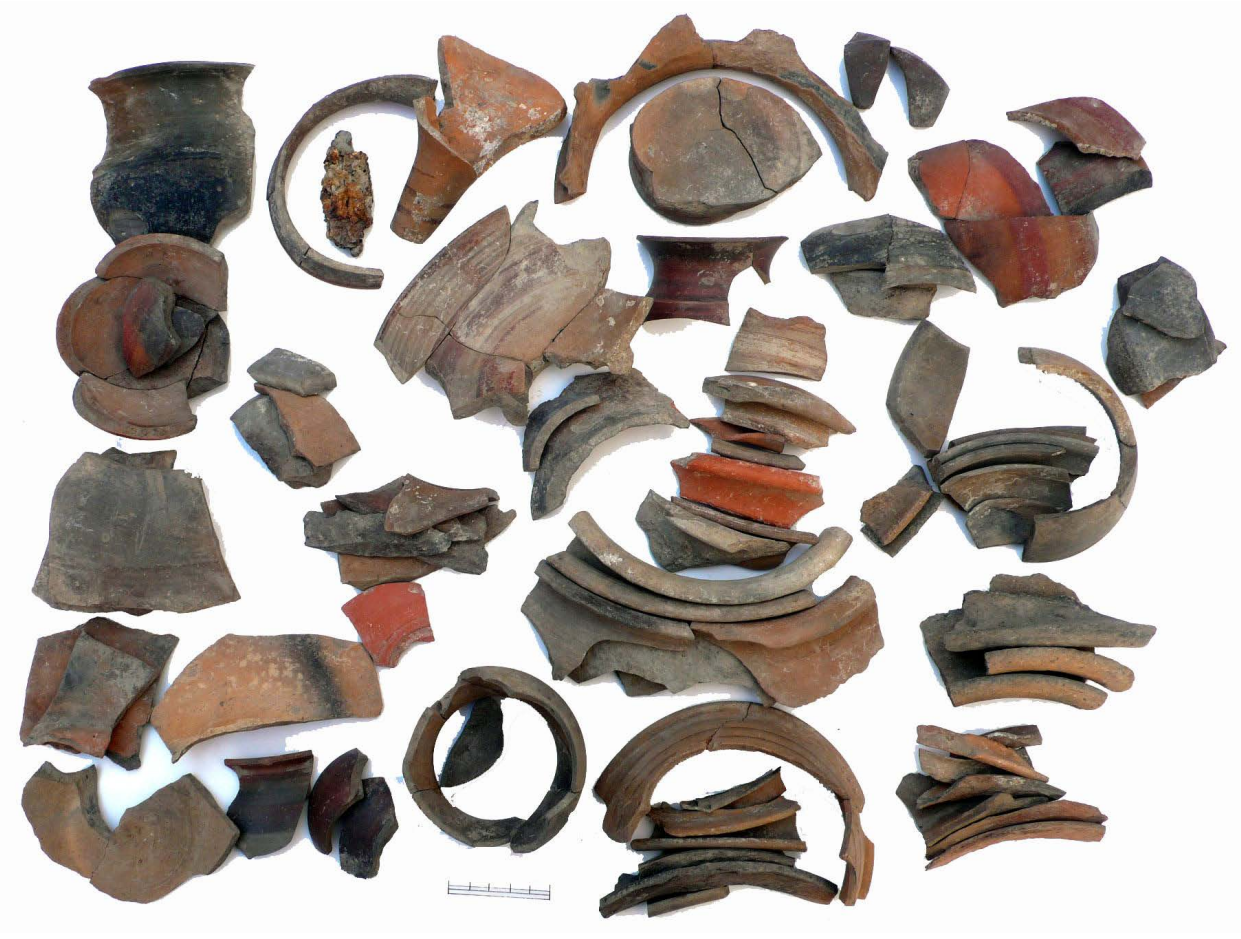

Figura 5. Fragmentos de vasijas quemadas recuperadas en la UE 2131, junto al acúmulo de granos de trigo.

granos, método que favorece su conservación o el malteado para la fabricación de cerveza. El malteado consiste en es dejar que los granos germinen sumergiéndolos en agua y después secarlos rápidamente mediante aire caliente. Son pocos las referencias que existen sobre el proceso de obtención de cerveza de la cebada en la Edad del Hierro a pesar de que numerosos fuentes indican su existencia, Hace años se interpreto una estructura para este fin en el yacimiento albaceteño de El Amarejo (Broncano y Blánquez 1985).

Otra posibilidad que se puede barajar es que se tratara de un alfar. En el castro de Las Cogotas, en Ávila, se hallaron los restos de unas estructuras extramuros que se interpretaron como las dependencias de un alfar. Entre ellas desatacamos la que se interpreta como pileta con recios muros de adobe, la base del horno circular y el obrador en donde una piedra similar a la que interpretamos como parte de un molino rotatorio, fue allí interpretada como la base del torno (Ruiz Zapatero y Álvarez Sanchís 2005). Lamentablemente, parte de estas identificaciones no están exentas de dificultades en Las Cogotas, y nada en el material cerámico, investigado hasta el momento, de La Gavia III sugiere de la existencia de un alfar.
Hacia el este se desarrollan de nuevo estructuras de tendencia cuadrangular y rectangular, afectadas por diversos agentes de modo que ha llegado a nosotros muy fragmentadas. Tienen en común unos suelos de tierra apisonada con evidentes signos de la acción del fuego, así como diversos acúmulos de materia orgánica igualmente quemada. En algunos casos, se pueden observar los restos de muros de adobe conservados por la acción del fuego, lo que nos habla de la posibilidad de que existieran más estructuras construidas con este material que al no haberse quemado no es posible diferenciar, y podría ser la explicación de la existencia de este espacio que aparece a nuestros ojos vacío.

En el norte se pueden distinguir dos estancias rectangulares conectadas, y un pasillo al otro lado: En el centro de la estancia mayor se encuentran los restos de un hogar. Más al este, se abre un nuevo espacio muy alterado.

En conjunto, los restos de estructuras hallados en este sector II no son fácilmente encuadrables dentro de una tipología urbana como sucedía con los de la cima del cerro, bien es verdad que el área excavada es menor y peor su estado de conservación. Aquí no se aprecia la presencia de agrupaciones regulares de es- 
tancias identificables como viviendas y la repetición de estos módulos, como es usual en la cima del cerro. Las estancias de tendencia cuadrada y rectangular, así como la posible agrupación en un vivienda de gran tamaño y de planta similar, recuerdan el ambiente encontrado en el cercano yacimiento de Santorcaz (Ruiz Zapatero et al. 2012 y Baquedano et al. 2007). Tampoco parece existir la dependencia de las estancias de un eje viario, sino que la disposición de las estructuras es mucho más variada. Existen numeroso indicios de espacios y estructuras más fácilmente identificables con actividades artesanales o de transformación que con verdaderas viviendas, un poco en consonancia con lo documentado en la barriada extramuros el Cerro de la Gavia (sector B). Con todo, la muestra es demasiado pequeña para establecer categóricamente esas diferencias.

\section{Materiales arqueológicos. Producciones cerámicas}

La mayoría de los materiales arqueológicos hallados son cerámicos. Los mayores volúmenes se recogen en los estratos que cubren las estructuras, espacialmente en la parte norte del Sector II. Se encuentran muy fragmentados evidenciando un abandono paulatino o al menos no traumático del lugar, y a la vez una fuerte alteración postdeposicional, especialmente debida a las labores agrícolas. Los restos cerámicos hallados en contextos primarios son escasos e igualmente fragmentados. Entre ambos conjuntos no existen diferencias sensibles en las proporciones de los distintos tipos cerámicos, por lo que es de suponer que el lapsus de tiempo entre unos y otros es pequeño. Es probable que tras el incendio de parta de las estructuras éstas fueran amortizadas pero que el uso posterior del espacio fuera muy corto, incluso podríamos suponer que el propio incendio se debiera a un estado de abandono o semiabandono del lugar.

En la UE 2000 que podemos considerar como la capa superficial que cubre a todo el Sector II, se recogieron 1.326 fragmentos cerámicos realizados a mano y a torno para cocina, no selectos, de tamaños medianos, y 878 de mayor tamaño, correspondientes a tinajas y grandes ollas, reductoras, 758 realizados a torno (131 de ellos, grises), no selectos, de tamaños medianos, y 947 de pequeño tamaño, pertenecientes a tinajillas, caliciformes, cuencos y escudillas.

Por lo que respecta a los primeros, se contabilizan 52 bordes rectos de tinajas reductoras, 2 de cazuelas, 45 bordes vueltos de grandes ollas reductoras, 19 de bordes engrosados con molduras, baquetones y hombros marcados, 9 de bordes vueltos y cuellos con molduras, 20 bases 10 de ellas planas, y el resto con pies anulares y umbilicadas, de ollas y 32 bases planas con ligero talón de tinajas reductoras, 11 galbos de tinajas estampilladas con triángulos, eses, círculos, espigas, equis y zetas, una tinaja reductora con estampillas en damero y borde recto que rebasa la pared al ext. e int., otra tinaja reductora con borde engrosado y hombro marcado, una tinajilla reductora con borde sub-triangular, tinajas reductoras con borde recto saliente, tinajas reductoras con bordes vueltos, tinaja reductora con borde triangular y hombro marcado, tinaja reductora con borde engrosado redondeado, una olla reductora con borde engrosado de sección cuadrada y otras ollas reductoras con borde vuelto. Amén de 50 fragmentos de tejas curvas.

Se documentan asimismo, 9 fragmentos de vasijas a mano: galbo con mamelón de perforación horizontal, borde indicado de cuenco semiesférico, alisado, bordes indicados de cuencos de paredes finas, alisados, bordes indicados ligeramente engrosados, de cuencos de paredes finas, alisados y borde indicado de cuenco semiesférico con pared gruesa, alisado. Todos ellos pueden encuadrarse dentro del período del Bronce Final/Hierro I. Constituyen la única evidencia que poseemos sobre la existencia de un asentamiento de estos momentos en el lugar.

Por lo que respecta a los productos a torno de pastas oxidantes y superficies cuidadas, se encuentran numerosos fragmentos de bordes con labios vueltos de pequeñas ollas de cocina, bordes engrosados pico de ánade caídos, bordes pico de ánade de tinajillas pastas anaranjadas, tal vez algunas pintadas con la pintura perdida, borde pico de ánade de tinajilla engobe naranja con líneas en negro, borde engrosado de paredes rectas, bordes pico de ánade y vueltos, tinajillas y caliciformes, borde redondeado de tinajilla, bordes pico de ánade y vueltos de tinajillas y caliciformes, bordes vueltos de tinajillas y caliciformes, grises, borde vuelto con pared recta con ondulaciones y bandas en rojo, bordes vueltos de caliciformes con hombro marcado y líneas en rojo vino- 
so, bordes vueltos o con pestaña de cuencos con líneas en rojo junto a borde, galbos curvos de urnas ovoides, bordes con pestaña de escudillas, borde redondeado curvado al interior de pasta anaranjada de cuenco con bandas en rojo, líneas junto a borde y $1 / 4$ de círculos, cuencos con banda roja al int. y ext., escudillas de bordes redondeados, abiertos o rectos, galbos de escudillas con superficies alisadas y bandas rojo al int.(23 fragmentos), escudilla con base pie, dos bandas rojo al ext., quemado, y engobe anaranjado, bases umbilicadas (9) y con pies anillados (12), base de pie alto de copita, bordes vueltos de ollitas alisadas en negro y gris, bordes vueltos de caliciformes grises de paredes finas y alisadas, bordes redondeados y apuntados de escudillas grises, dos galbos grises con decoración a ruedecilla, dos galbos de cuello de caliciforme con cenefa con incisiones diagonales en hombro, 65 galbos pintados con decoraciones geométricas: bandas, líneas, $1 / 2,1 / 4$ círculos, etc.

Destacamos finalmente fragmentos de tonel, un borde trilobulado de jarra, borde ala horizontal tal vez de un kalathos, borde de cuello estrecho de botella, asas de $0,6,1$, y $2 \mathrm{~cm} \varnothing$, un borde recto abierto con línea y 5 líneas perpendiculares de vasija pintada de tradición indígena, 4 bordes abiertos de cuencos con barniz rojo al ext., y 4 bordes apuntados rectos de cuenquitos de barniz rojo, y 38 pintadas de tradición numantina, de pasta blanca con engobes salmón y decoraciones geométricas.

En los rellenos de las estructuras del extremo norte del área se recogen medio millar de fragmentos cerámicos y en el estrato que las cubre casi un millar, entre los que se pueden destacar más de un centenar pertenecientes a varios toneles, así como dos fragmentos de borde de ánfora Dressel 1. Se documenta además una fíbula de tipo omega a la que faltan los remates, pero que podría encuadrarse dentro del tipo 35.1.a.1, de Erice (1995), con aro de sección circular e inicio de los remates muy delgado, encuadrada en época republicana. Por su parte González Zamora las incluye dentro de los tipos B.1 y B.2 de acuerdo a la longitud de los terminales, correspondiendo los primeros más cortos a época pre-sertoriana y los segundos entre el 100-75 a.C.

La mayor concentración de recipientes a torno de toda la excavación se localiza en la UE 2131, en el extremo suroccidental del Sector II, junto al agujero (2066) en donde se hallaron abundantes granos de cereal quemados.
Se trata de un conjunto fuertemente alterado por el fuego, en el que predominan los bordes de caliciformes y bases con pies anillados de cuencos decorados con bandas y líneas en rojo. Todas las decoraciones mencionadas presentan características de los momentos finales del la Edad del Hierro, que podemos resumir en la presencia de bandas rojas hacia la mitad de los recipientes, a menudo delimitadas por líneas negras e incluso con líneas negras en el centro de la banda, y engobes marrón claro o anaranjados combinados con bandas rojo, con superficies alisadas en los cuencos. Estas características anticipan los esquemas decorativos que heredarán las cerámicas denominadas "pintadas de tradición indígena", de las que se han hallado algunos fragmentos aislados.

Una de las características más destacadas de este yacimiento, en cuanto a las producciones cerámicas se refiere, es la presencia de las producciones que podemos denominar genéricamente como numantinas o Meseta Norte. Se trata de recipientes con pastas blancas o amarillentas, que suelen llevar un engobe o aguada que varía del marrón claro al anaranjado y del color carne al salmón. Sobre esta aguada se suelen disponer motivos pintados con trazos finos en color rojo oscuro que puede llegar al negro. Los temas se pueden reducir a sencillas líneas o dobles líneas, como vemos en numerosos fragmentos de caliciformes de gran tamaño, que presentan una línea bajo el borde y otra u otras dos marcando el arranque de la curvatura del hombro. Como en el caso de los caliciformes de tipo ibérico, las bases pueden ser con pie anillado, o umbilicadas. En otros recipientes más pequeños, como cuencos, escudillas e incluso caliciformes, se pueden complicar los motivos decorativos, incluyendo pequeños círculos concéntricos, acompañados de melenas, y series de ondas que se disponen bajo el borde. Son frecuentes los galbos con baquetón sobre el que se dispone una banda roja delimitada por líneas negras y a ambos lados sendas series de ondas. No se han hallado ejemplares con decoraciones figuradas.

Este tipo de productos son característicos de yacimientos como Numancia desde la segunda mitad del siglo II a.C. hasta mediados del I a.C. También están presentes en yacimiento abulenses como en Las Cogotas y otros del ámbito vacceo como Pintia. Aunque los porcentajes en cada UE son pequeños, casi igualan a los de las producciones grises, muy por encima de los barnices rojos, y su proporción es constante 

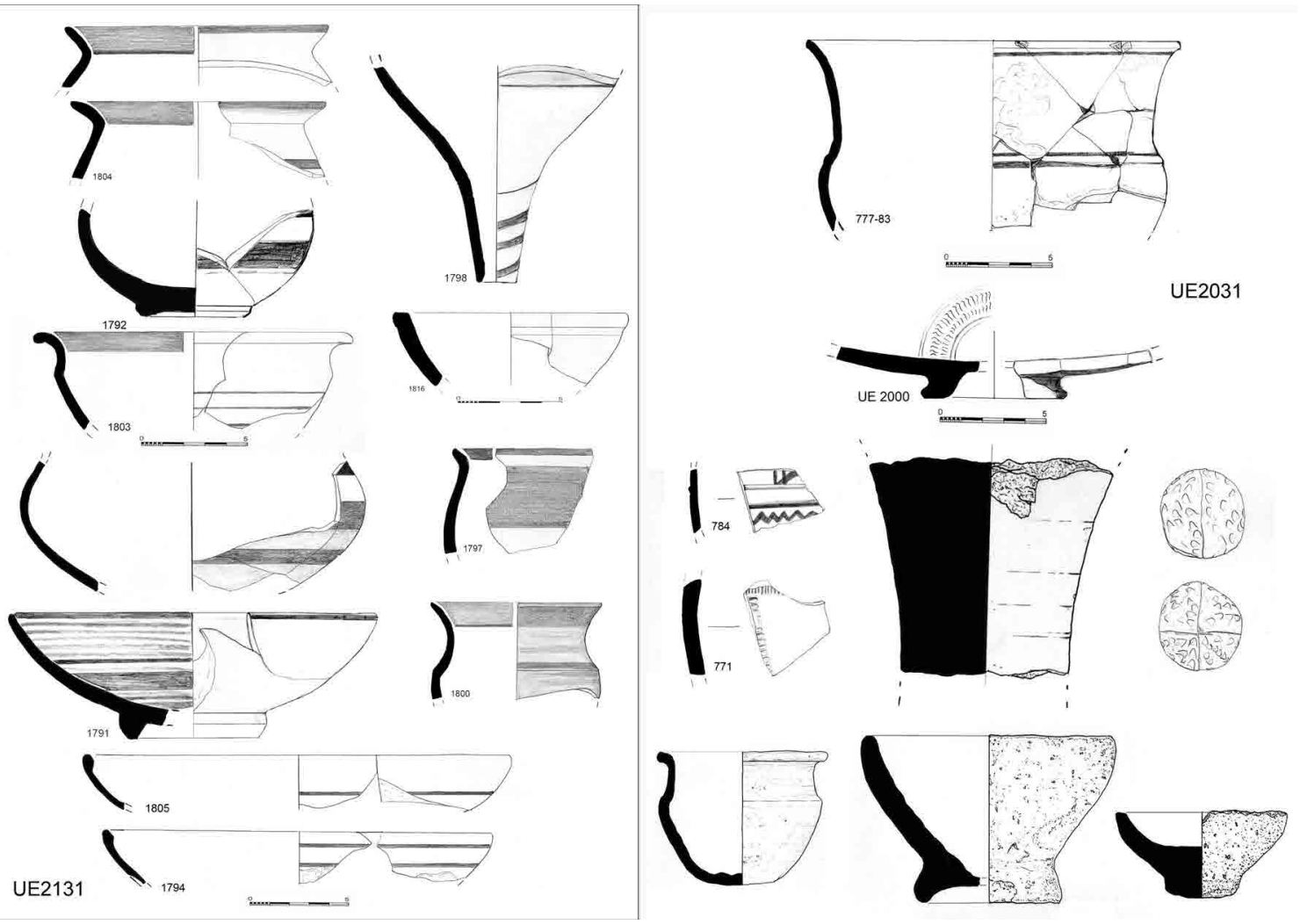

Figura 6. Cerámicas de la UE 2031 con elementos de importación y 2131 (vasijas quemadas junto a la concentración de granos).

en todos los contextos, a diferencia de lo que ocurría en lo alto del cerro, donde se hallaron ejemplares más vistosos con decoraciones figuradas, pero con proporciones menos representativas. Sin duda, estos tipos cerámicos añaden una peculiaridad propia a los conjuntos cerámicos de finales de la Edad del Hierro del Sureste de Madrid, ya que parecen estar igualmente representados en yacimientos cercanos como el de Santorcaz, y por el contrario no se documentan al Sur del Tajo. Los influjos o la presencia de producciones propias del ámbito celtibero, se confirma con la presencia de una bola de barro de las llamadas "cánicas" que tan frecuentes son en yacimientos como Numancia.

Por último, nos referimos a los productos de importación entre los que ya hemos mencionado la presencia de algunos cuencos y escudillas del llamado barniz rojo púnico que no superan la decena de ejemplares. En diversos contextos del Sector I y II han aparecido fragmentos de ánfora que pueden adscribirse al tipo Dressel 1, procedentes de la región tirrénica, con pastas campano-etruscas, o las grecoi- tálicas tardías. En todo caso, con cronologías de mediados del II a mediados del I a.C., que se complementan con las fechas que se barajan para las cerámicas de tipo numantino. También destacan un borde de botella o askos pintado en negro y una base con pie y decoración a ruedecilla interior de barniz negro, que podría englobarse dentro de las producciones b-oides de Cales, con cronología del 130-120/90-80 a.C.

\section{Materiales arqueológicos. Metales}

En toda el área II se recogieron numerosos fragmentos amorfos de hierro y escorias, además de varios clavos. Aunque es común la presencia de hierro en los poblados tardíos de la Edad del Hierro, el volumen hallado en La Gavia III no es desdeñable, de modo que no se puede descartar la existencia de alguna pequeña herrería o fragua. A diferencia de un alfar que podía surtir con sus productos a muchos poblados, las fraguas debieron ser más abundantes y es probable que casi en cada poblado 


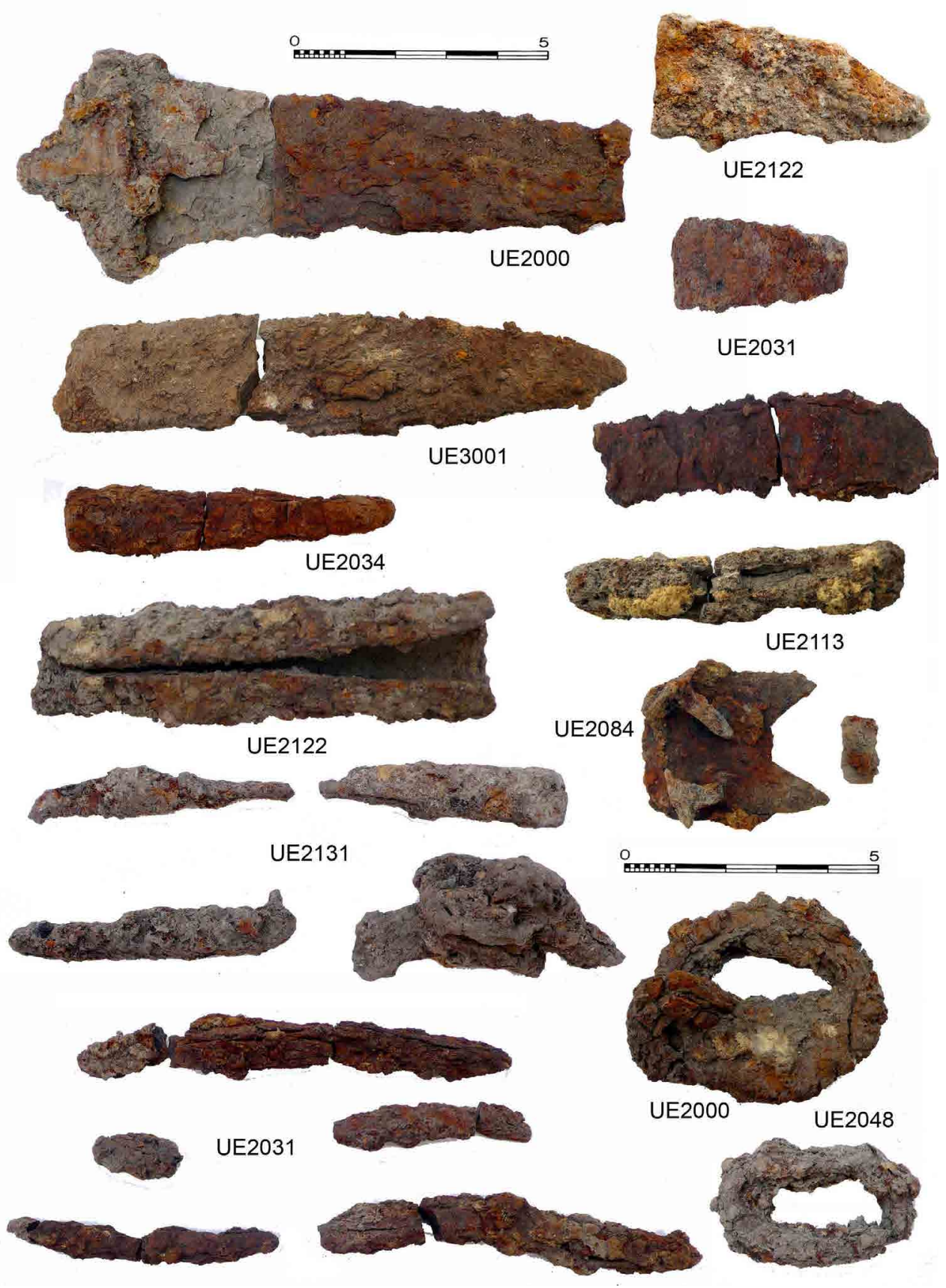

Figura 7. Algunos de los útiles y herramientas de hierro recuperadas en el Sector II.

existiese una, aunque el registro arqueológico ha sido parco hasta el presente en la constatación de este tipo de estructuras.

Por ejemplo, en la UE 2000 se hallaron 50 fragmentos amorfos de hierro y de escorias, 4 pequeños fragmentos de sección redonda $\mathrm{y}$ uno de $22 \mathrm{~cm}$ que podría ser moderno, varios fragmentos de anilla con hembrilla de $5 \mathrm{~cm} \varnothing$, de sección gruesa de $1 \mathrm{~cm}$, y otros de cuchillo con hoja de $10 \mathrm{~cm}$ largo conservado, ancho máximo de $4 \mathrm{~cm}$, con el remache de hierro para alojar el mango. Podría tratarse de un puñal de mango biglobular, aunque la hoja es muy estrecha para la norma en este tipo de puñales, y además los bordes exteriores son rectos, teniendo la hoja una planta de triángulo isósceles, cuando es común que en estas armas las hojas sean más anchas y tengan un ligero estrechamiento en el centro. En bronce, dos fragmentos esféricos pequeños, uno rectangu- 


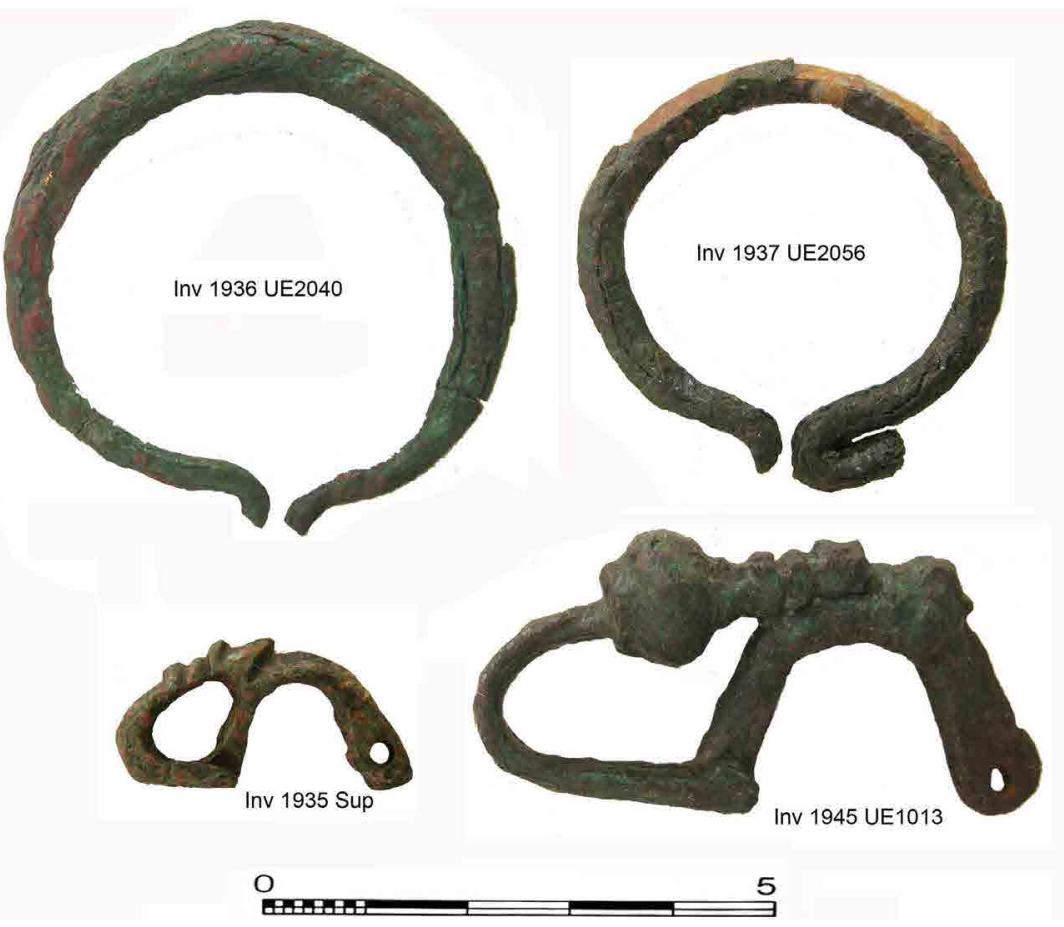

Figura 8. Fíbulas halladas en La Gavia III.
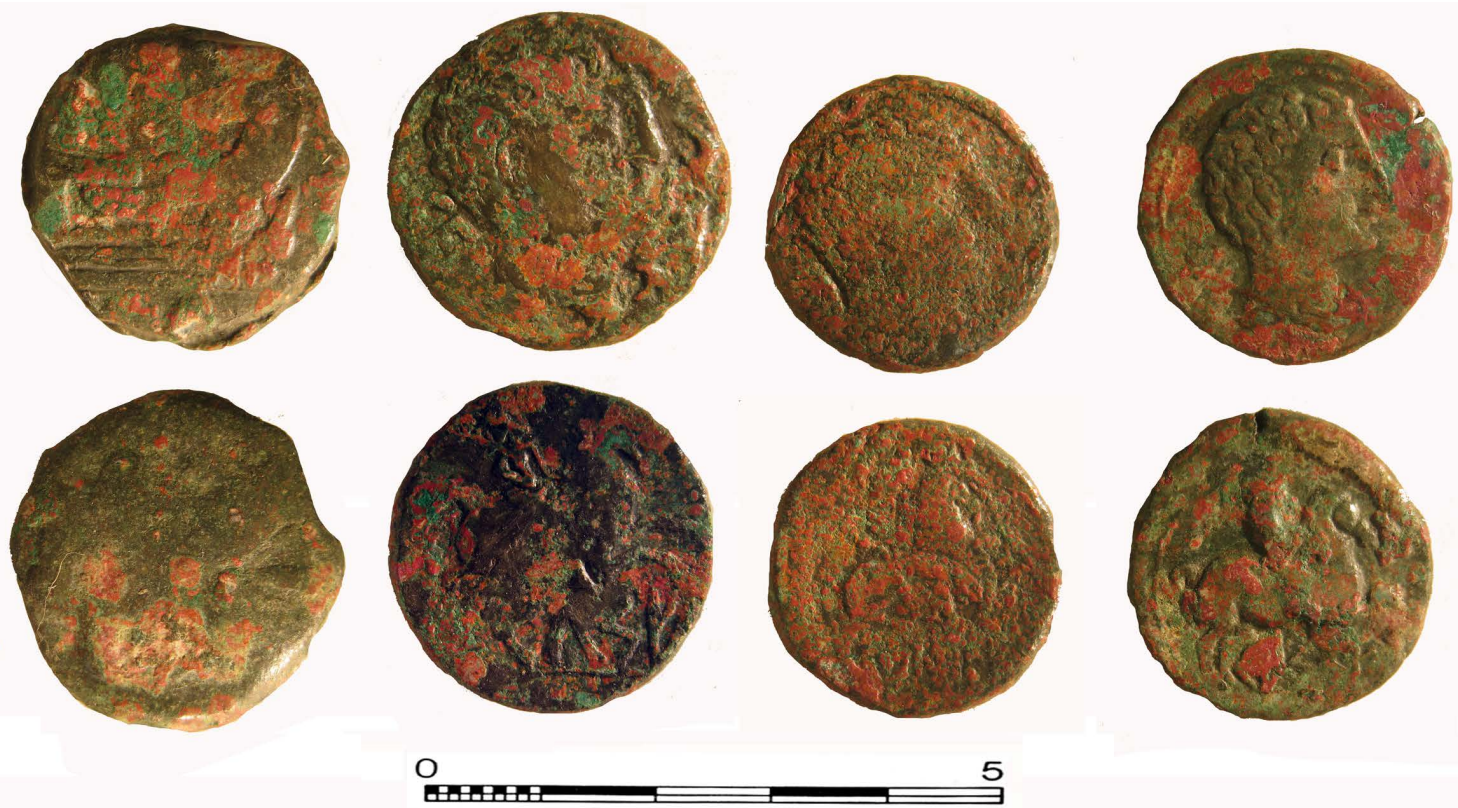

Figura 9. Monedas halladas en los niveles superficiales de Gavia III.

lar de $2 \times 2 \times 1 \mathrm{~cm}$, un remache y una lámina de $1 \mathrm{~cm}$ doblada en forma de gancho, además de una fíbula de pie vuelto de La Tène, de la Serie III de González Zamora (1999), de puente fundido y arco peraltado. En concreto de la serie III.3.1.2. que este autor describe como: con remate principal en un semibicono ... retenido entre collarines. Es un producto abundantísimo del final sertoriano ... Fíbulas frecuentísima en las estaciones carpetanas tar- 
dias: Muela de Taracena, Santorcaz y Fosos de Bayona (p.270). En concreto el ejemplar de La Gavia tiene paralelos muy próximos en las fíbulas $n^{\circ} 375$ y 76 de Muela de Tracena y 477 de Yeles, del catálogo de este autor, quien les da una cronología de mediados del siglo II al 70 a.C.

En total se encontraron 4 fíbulas, dos de ellas de las llamadas de Omega y otras dos de de pie vuelto o La Tène, de la Serie III, de puente fundido y arco peraltado. Este tipo de fíbulas es un producto abundantísimo en el período sertoriano de la primera mitad del siglo I a.C. así como en las estaciones carpetanas tardías: Muela de Taracena (Guadalajara), Santorcaz y Fosos de Bayona (Madrid), etc. (González Zamora 1999).

Finalmente comentamos 4 monedas halladas igualmente en los niveles superficiales. Se trata de ases, uno de ellos con busto viril a la derecha en el Anverso y Reverso con Jinete con lanza, a la derecha, de imposible lectura. Otro corresponde a un As de CESE (KESE), Tarragona, con Anv/ Cabeza viril con manto a dcha. y letra R. Rev/Jinete con palma a dcha. y debajo leyenda en caracteres ibéricos KESSE (-esse). Este ejemplar sería de finales del s. II a.C. Con la leyenda ibérica kese. Una tercera corresponde a otro As de Celse (Velilla del Ebro, Zaragoza). Anv/Cabeza viril a dcha. con 2 delfines y leyenda CEL. Rev/ Jinete con palma a dcha. y debajo, sobre línea, CELSE (o KELSE) en caracteres ibéricos, de mediados de siglo I a.C. La última moneda corresponde a un As con proa de galera en el reverso. En el anv/ busto de Jano Bifronte. Período Republicano, acuñado en Roma. En función de su peso debió ser acuñada entre 169 y 158 a.C, Se trata de uno de los primeros tipos monetales emitidos por Roma ${ }^{3}$.

\section{Materiales arqueológicos. Ecofactos}

En las actuaciones arqueológicas modernas no se concibe una excavación si no va acompañada de una serie de analíticas que deberían considerarse obligadas dentro de los protocolos de recogida de restos arqueológicos. En la actuación de La Gavia III concretamente, se realizaron estudios de fosfatos, materia orgánica, antracológicos, palinológicos, carpológicos, de fitolitos, de psuedomorfos, faunísticos, antropológicos, de malacofauna, de industria lítica y de radiocarbono.

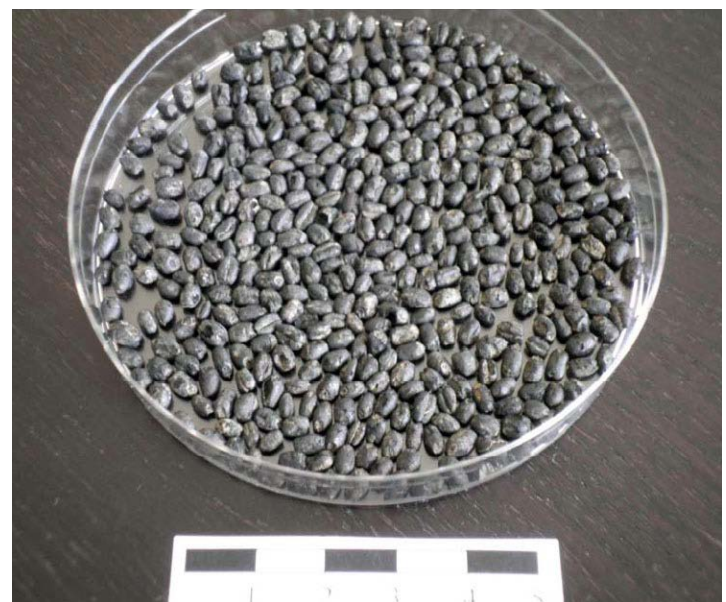

Figura 10. Semillas de trigo de la UE 2066.

El espectro polínico se encuentra claramente dominado por Cichorioideae (Asteraceae

liguliflorae o compuestas con lígulas). En menor medida aparecen las familias Asteraceae tubuliflorae y Cardueae. Se trata de familias exclusivamente herbáceas, muy frecuentemente anuales, que pueden desarrollar praderas. Es habitual que en suelos alterados antrópicamente se comporten como ruderales. También crecen bien en terrenos cultivados o baldíos como plantas arvenses. Así pues, estos taxones debieron constituir un paisaje abierto, con una cobertura vegetal escasa y una diversidad baja.

La gran mayoría del resto de taxones identificados son fundamentalmente anemófilos y grandes productores de polen. Es el caso de Pinus. Este taxón, que ha sido identificado tanto políticamente como en el análisis antracológico, debió ser abundante en los alrededores del yacimiento y representa una vegetación de tipo regional e incluso extraregional. Los valores bajos de sus porcentajes nos indican una señal lejana. Lo mismo ocurre, aunque en menor medida debido a su menor producción polínica, con Chenopodiaceae/Amaranthaceae. Dado el carácter abierto del paisaje es probable que Chenopodiaceae/Amaranthaceae y Poaceae sí tuvieran cierta importancia en las inmediaciones de la zona de estudio. Las quenopodiáceas son plantas ruderales, a menudo nitrófilas, que proliferan fácilmente en lugares donde se produce actividad humana.

Por lo que respecta a los restos de carbones, se hallaron en dos estratos grandes concentraciones, de los cuales se han podido identificar tan sólo la mitad de ellos, que en todos los ca- 
sos corresponden al género pinus. Debe tratarse de los restos de unos postes quemados utilizados para edificación, aumentando los datos sobre el empleo de este tipo de madera que ya se tenían del poblado del alto del cerro.

Los restos carpológicos analizados se centraron especialmente en el conjunto de granos quemados de la UE 2066, con 2612 semillas carbonizadas de trigo (Triticum sp.), de diferentes especies, dominando el tipo aestivum/ durum. También se han recuperado 1081 fragmentos parciales de Triticum sp. Mucho menos representada, ha aparecido la cebada: 9 semillas carbonizadas del género Hordeum. El tipo dominante en La Gavia III ( $T$. aestivum/ durum) está mejor adaptado que otros a las duras condiciones mediterráneas, sobre todo a la sequedad prolongada del suelo. Se documentaron además algunas semillas de herbáceas, entre las cuales Rumex es un género amplio muy bien representado en la Península Ibérica. Todas sus especies son herbáceas y requieren una elevada humedad edáfica, que a menudo encuentran en bordes de ríos o acequias de zonas antropizadas, ya que muestran un carácter fuertemente nitrófilo ${ }^{4}$.

La amplia presencia de triticum aestivum durum constrasta con la de cebada desnuda (hordeum vulgare/nudum: 10.000 semillas) detectadas en un depósito del poblado del cerro. Al tratarse de depósitos usualmente quemados in situ, es frecuente que se trate de conjuntos monoespecíficos, de modo que hay que tener precauciones a la hora de establecer consideraciones generales sobre la extensión de una $\mathrm{u}$ otra especie en los repertorios generales de un yacimiento.

Por lo que se refiere a la fauna, predominan aquí también las especies domésticas, principalmente las ovejas y las cabras, que constituirían la cabaña ganadera típica de estas regiones todavía hoy. La estrategia de explotación de estos animales parece orientarse, sin embargo, a la optimización de la carne ya que hay pocos adultos y predominan los individuos juveniles y subadultos. Tal vez la poca amplitud de la muestra sea la responsable de esta característica. El vacuno sería la segunda cabaña en importancia aunque a mucha distancias de los ovicaprinos. Los restos de cerdo tampoco son muy abundantes, con animales también jóvenes, al parecer utilizados para el aprovechamiento de su carne. Los équidos son bastante marginales y dentro de ellos los caballos muy escasos, estando mejor representado el asno.
Se evidencia también aquí la presencia del perro, así como de la gallina.

Entre las especies cinegéticas, cuya presencia representa pequeños porcentajes en el conjunto de la muestra, destacan, como en el poblado de la cima del cerro, el ciervo, conejos y liebres. También está presente el tejón y la perdiz, junto con la grulla ${ }^{5}$.

\section{Cronología}

Como ya hemos indicado, todos los indicios apuntan hacia un abandono paulatino del emplazamiento, de modo que sólo se dejaron en él aquellos fragmentos de vasijas, adornos y herramientas que ya eran inservibles. Los conjuntos cerámicos que hemos descrito anteriormente correspondientes a los niveles superficiales del yacimiento, pueden encuadrarse en la primera mitad del siglo I a.C., tal vez dentro del primer cuarto. Los fragmentos de ánforas así como los del plato campaniense remiten a momentos en torno al cambio del siglo II al I a.C., y en una horquilla del 140 al 70 a.C. pueden encuadrarse asimismo las fíbulas encontradas. El as de Cesse entraría también dentro de ese período, y el de Celse tal vez unos años más tarde. Por lo que respecta al ejemplar de Jano y Proa su acuñación es más temprana, de mediados del siglo II a.C.

Se tomaron dos muestras para análisis radiocarbónicos, una de fragmentos tierra quemada (294870) y el otro de las semillas de trigo de la UE 2066 (294871). Se obtuvieron estos resultados:

Beta 294870: $\quad 60 \pm 40$ BC Cal 16040BC a 1sigma y Cal 190BC-10AD a 2 sigma. Beta 294871: $\quad 160 \pm 40$ BC Cal 390$350 \mathrm{BC}$ y a Cal 290-220BCa 1sigma y Cal 400200BC a 2 sigma.

La Muestra 294870 que proporciona una fecha de $60 \mathrm{BC}$ y se va a $160-40 \mathrm{BC}$ a 1 sigma, entre dentro de la horquilla cronológica en la que pueden encuadrar la mayoría de los materiales arqueológicos. La segunda de las muestras: 294871 ofrece resultados más antiguos. La procedencia y características del material con el que se realizó el análisis radiocarbónico, invitan en principio a suponer una calibración más fiable. La calibración a 1 sigma ofrece dos intervalos: $390-350$ y 290-220 a.C. Si tomamos el segundo nos acercamos más a la fecha 
de acuñación del as de Jano y la Proa. De todos modos el intervalo de tiempo entre la fecha en la que pudo quemarse el cereal y el momento del abandono: mediados del siglo III a mediados del II a.C. y mediados del I a.C., nos parece demasiado largo por todas las consideraciones que hemos expuesto anteriormente.

\section{Conclusiones. La Gavia III y el pobla- miento de La Gavia en el contexto del final de la Edad del Hierro en la Comunidad de Madrid}

La localización del poblado del Cerro de la Gavia se realizó hace años, aunque sólo tras la intervención de 1999-2000 (Quero et al. 2005) fue posible su correcta valoración e inclusión dentro de los recintos amurallados carpetanos característicos de los valles fluviales de las provincias de Madrid y Toledo, caracterizados por entones en otro estudio sobre la comarca de la Mesa de Ocaña (Urbina 2000). El poblado se puede enclavar por tanto dentro de la tipología de recintos amurallados de la II ${ }^{\mathrm{a}}$ Edad del Hierro de espolón con foso y barrera, en este caso en pleno valle fluvial y aprovechando los escarpes yesíferos, como otra veintena de ejemplos hoy conocidos en estas regiones. Se trata de un enclave de pequeño tamaño $(1 \mathrm{Ha})$ similar, por ejemplo, al toledano de Plaza de Moros (Urbina 2012). .Estos recintos comienzan su andadura a lo largo del siglo IV a.C. como se ha dicho hace tiempo (Urbina 2000: 212 y ss.). Las cerámicas áticas de La Gavia correspondientes a los niveles más antiguos no hacen sino corroborar estas fechas.

Pero los paralelismos con otros lugares conocidos acaban ahí, ya que los recintos B, $\mathrm{C}$ y Gavia III investigados en los alrededores del poblado, no tienen de momento paralelos, probablemente más debido al hecho de la falta de investigaciones que de su inexistencia. Es extremadamente difícil encontrar en la bibliografía sobre el final de la Edad del Hierro en el Península Ibérica investigaciones que profundicen más allá del propio yacimiento nuclear, sin duda por los grandes costes que ello conlleva, pues los presupuestos generalmente apenas alcanzan para investigar una pequeña parte de los poblados, y la localización precisa de estructuras en sus inmediaciones suele ser ardua y costosa. Es por ello que la oportunidad que ofrecen ciertas obras como es el caso de las presentes, hay que verlas como una oportu- nidad de investigación arqueológica que no se daría de otro modo (Morín et al. 2012).

El barrio B exterior al foso a septentrión del poblado de La Gavia, las estructuras del sector $\mathrm{C}$ a poco menos de $1 \mathrm{~km}$ del poblado, ya situadas en pleno páramo, y la gran barriada o extensión del poblado localizado a los pies del cerro en plena vega del Manzanares: Gavia III, completan una realidad mucho más compleja de la que se venía presuponiendo para estos enclaves. Este hecho es crucial ya que nos obliga desde el mismo momento de su conocimiento, al detallado examen de los alrededores de cualquier otro poblado de características similares, pues ahora sabemos que es más que probable la existencia de otras evidencias arqueológicas que el mero núcleo central. En ese sentido las investigaciones de La Gavia han abierto las puertas a una nueva concepción del espacio humano de la Segunda Edad del Hierro en el centro peninsular.

Otro de los aspectos que juzgamos más relevantes son las fechas de abandono del poblado amurallado, si bien en realidad, ambas condiciones van de la mano. Hasta no hace mucho era común pensar que la vida en este tipo de recintos no se prolongaría más allá del periodo de guerras comprendido entre la llegada de los cartagineses y la conquista de estas tierras por los romanos: 220-179 a.C. La presencia de materiales romanos en algunos de estos recintos fortificados: Valderretamoso (Ciruelos), Sotomayor (Aranjuez) se ha desligado del hábitat indígena suponiendo la existencia de vacíos temporales en la ocupación de estos lugares, como ocurre por ejemplo en Titulcia o la propia Toledo, donde se levantarán después ciudades romanas. Muchos de estos recintos debieron ser destruidos a comienzos del siglo II, tal y como sucedió con Aebura, Dipo, Certima, Alce, etc. Otros, no obstante, se debieron rendir sin que el asentamiento fortificado fuera derruido.., escribíamos hace años uno de nosotros (Urbina 2000: 238 y ss.). La propia morfología de estos hábitats, aprovechando cerros testigos, penínsulas y espolones y delimitando el espacio por medio de murallas, parecía sugerir la nuclearización del espacio y anular la posibilidad de un hábitat extramuros. Aunque desde finales de los 90 documentamos en prospección un espacio ocupado al exterior de la barrera de Plaza de Moros (Urbina 2000 y 2012), al estar dentro del recinto de la península en donde se levanta el yacimiento, era difícil no ligarlo directamente al recinto amu- 
rallado. La constatación de una pervivencia del poblamiento más allá de los períodos bélicos del siglo II a.C. en La Gavia, abría la puerta a la posibilidad de la existencia de hábitats fuera de los recintos amurallados, algo que se constató en aquella misma intervención arqueológica (Quero et al. 2005).

Los descubrimientos de La Gavia III vienen a matizar y complementar aún más estos aspectos, mostrando el modo en que la romanización se va imbricando poco a poco sobre comunidades indígenas sin necesidad de que estas abandonen sus hábitats originales. En este sentido los hallazgos de la Gavia muestran un camino bien diferente a los de un lugar relativamente cercano y contemporáneo como el Llano de la Horca en Santorcaz (Baquedano et al. 2007 y Ruiz Zapatero et al. 2012). Este yacimiento lo consideramos hace años como un ejemplo de los nuevos enclaves creados o auspiciados por Roma, como la plasmación urbana de los primeros intentos de reorganizar un territorio ya bajo la órbita romana (Urbina 2000: 238 y ss.). Otros casos de función similar aunque de morfología diferente serían los del Cerro del Gollino (Santos, et. al. 1998) en Corral de Almaguer (Toledo), o incluso el de Fosos de Bayona, identificada con la ciudad indígena de Kontrebia Karbica (Gras, et. al. 1984). Siempre hemos mantenido que Fosos de Bayona no se corresponde con un hábitat indígena típico de la Segunda Edad del Hierro. La existencia en sus alrededores de los recintos fortificados del Cerro de los Espejares y Cerro Sopeta o Castillejo, no hacen sino confirmar esa impresión. Su cronología con inicios en el siglo III, así como su momento de abandono son bastante coincidentes con los del Llano de la Horca, por lo que no sería extraño que respondiesen a fenómenos similares. Todos estos hábitats de orígenes tardíos, con morfología en llano, de extensiones mucho mayores que las usuales para los asentamientos indígenas, deben estar relacionados de uno u otro modo con los acontecimientos bélicos de fines del siglo III-inicios del II a.C., y su florecimiento con los inicios de la dominación romana.

Probablemente después de las campañas bélicas de la década de 180 a.C., y desde luego tras el impulso que debió suponer para estas regiones el acuartelamiento de los ejércitos que combatían en Numancia, (cif. 135 a.C. Apiano, Ib.83) el recinto en la vega de Gavia III debió crearse y prosperar. A mediados del s. II el Sur del Tajo es un territorio adherido totalmente a los romanos. La propia Roma aparecerá ahora como garante de los grupos carpetanos del Tajo, cómo expresa la campaña de Lúculo contra los vacceos (Apiano, Ib.51) y las posteriores correrías de Viriato por estas tierras. Ha pasado una generación desde las campañas bélicas del 179 a.C. en un período de paz instaurado tras los acuerdos de Graco. Tiempo más que suficiente para sea visible un aumento de la población, que también pudo deberse en parte a la llegada de gente desde algún otro lugar de las cercanías. En cualquier caso el crecimiento poblacional parece notorio, así como el incremento de las actividades de transformación o del desarrollo de pequeñas industrias ahora más demandadas, como la alfarería, la herrería, el mayor consumo de grano, tal vez incluso un pequeño cambio en el patrón de utilización de los animales domésticos con ovejas y cabras sacrificadas más jóvenes para aprovechar su carne.

La creciente presencia romana en la zona no es ajena a este desarrollo, pero todavía las pautas de vida y sus señas externas pueden considerarse plenamente indígenas. La romanización, por tanto, se va introduciendo en la forma de vida nativa muy paulatinamente, afectando en primer lugar al aumento de los objetos exóticos que llegan en mayor cantidad debido a un florecimiento general de las redes comerciales regionales. Poco después se observa un aumento de procedencias diversas entre los bienes de consumo, y finalmente llegamos al comercio directo de productos latinos y el cambio de patrones de asentamiento. Pero en la Gavia aún no se han dado esos últimos pasos, aún el comercio directo es escaso, mucho menor que lo es por entonces en otros lugares, especialmente aquellos núcleos que desde un tiempo vienen funcionando como nodos del nuevo orden que va imponiéndose, como lugares centrales de un incipiente ordenamiento territorial auspiciado por Roma, cual parece ser el caso del Llano de la Horca, donde los postreros habitantes más que los últimos carpetanos (Zapatero et al. 2012) habría que considerarlos como los primeros romanos.

Esa romanización que se extiende lentamente como una mancha de aceite, abre las comunicaciones. Y este es otro de los aspectos importantes a resaltar de las investigaciones arqueológicas en La Gavia. Sorprendentemente, en las excavaciones de1999-2000 se puedo comprobar el gran peso que tenían los productos alfareros propios de la Meseta Norte entre 
sus conjuntos cerámicos, por entonces prácticamente desconocidos en estas tierras al sur del Sistema Central (Morín y Urbina 2012). Más tarde, han ido apareciendo estas mismas cerámicas bien conocidas en los ámbitos tardíos celtíberos y vacceos en otros lugares como Santorcaz, Fuente de la Mora e incluso Toledo. La ausencia de estas producciones al sur del Tajo nos hace plantearnos por el momento hasta que punto un río puede llegar a constituir una frontera más solida que una cadena montañosa. También debiera ser motivo de reflexión para todos aquellos defensores de unos grupos étnicos prerromanos para los que nunca se ha hallado justificación textual en las fuentes (antes al contrario) ni documental entre los conjuntos arqueológicos. Hemos asistido en los últimos años a una proliferación del uso de términos como "carpetano" empleado sin discriminación para calificar todo lo que se encuentre dentro de un territorio definido de antemano por investigadores modernos, llegando al absurdo de hablar de cerámicas carpetanas, estructuras carpetanas e incluso hornos carpetanos Los conjuntos cerámicos de La Gavia, por hablar de los restos más abun- dantes hallados en los yacimientos, así como los de Santorcaz (Märtens et al. 2009), tienen numeroso puntos de coincidencia con los de necrópolis del Duero como Pintia (Sanz y Velasco 2003), consideradas vacceas, o las celtiberas del valle del Ebro, por ejemplo Segeda (Burillo et al. 2007), que las que se puedan establecer con otros lugares más cercanos y considerador "carpetanos" como Plaza de Moros en Villatobas (Urbina et al. 2004).

El antiguo recinto amurallado de La Gavia continuó siendo el núcleo habitacional principal: allí se encuentran en mayor medida los productos más lejanos como las cerámicas campanienses y de barniz rojo, mientras que el asentamiento de la vega debió funcionar más como un barrio artesanal en el que las pequeñas industrias podían convivir con las viviendas de aquellos que ya no cabían en el antiguo recinto. El enclave fue declinando paulatinamente al tiempo que nuevos núcleos situados en lugares más acordes con las nuevas rutas y los nuevos intereses agrícolas se debían ir desarrollando en los alrededores. Hacia la mitad del siglo I a.C. La Gavia debió ser ya un lugar casi fantasma.

\section{Notas}

3. Estudio numismático ha sido realizado por P. Guerra.

4. Los estudios palinológicos, antracológicos y carpológicos fueron realizados.

5. Estudio faunístico ha sido realizado por J. Yravedra.

\section{Bibliografía}

Abad, L.; Sala, F. (1993): El poblado ibérico de El Oral (San Fulgencio, Alicante).Valencia.

Alonso, N. (1999): La agricultura de la Primera Edad del Hierro y de la época ibérica en el llano occidental catalán: Problemática y nuevas aportaciones. Els productes alimentaris d'origen vegetal a l'Edat del Ferro de l'Europa occidental: De la producció al consum. Girona, 127-138.

Baquedano, E.; Contreras, M.; Märtens, G.; Ruiz Zapatero, G. (2007). El oppidum carpetano de "El Llano de la Horca (Santorcaz, Madrid). Zona Arqueológica, 10, vol. II: 374-394.

Blasco, M. ${ }^{\text {a C.; }}$ Alonso, M. ${ }^{\mathrm{a}}$ A, y Valiente, S. (1980): La Edad del Hierro en la provincia de Madrid. II Jornadas de Estudios sobre la Provincia de Madrid. Madrid, p. 47-57.

Blasco, M. ${ }^{\mathrm{a}}$.; Barrio, J. (1991): Las necrópolis de la Carpetania. En Congreso de Arqueología Ibérica: Las necrópolis, Madrid, p. 279-312.

Broncano S.; Blánquez, J. (1985): El Amarejo (Bonete, Albacete). Excavaciones Arqueológicas en España.

Burillo, F.; Cano, Ma a.; López, R.; Saiz, E. (2007): Procesos de cambio cultural en la cultura celtibérica ante la llegada de Roma. Un análisis a partir de las excavaciones en Segeda I, área I. As Idades do Bronze e do Ferro na Península Ibérica. Actas IV Congresso de Arqueologia Peninsular, 14-19 Setp 2004, Faro, 341-350.

Erice, R. (1995): Las fíbulas del Nordeste de la Península Ibérica: siglos I A.E. al IV D.E. Zaragoza.

Fuidio, F. (1934): Carpetania Romana. Madrid. 
Gast, M.; Sigaut, F. (1985): Les techniques de conservation des grains à long terme: leur rôle dans la dynamique des systèmes de cultures et des sociétés. Paris.

González Zamora, C. (1999): Fíbulas en la Carpetania. Madrid.

Märtens, G.; Contreras, M.; Ruiz, G.; Baquedano, E. (2009): El Llano de la Horca (Santorcaz). Un asentamiento carpetano en los albores de la romanización". Actas de las Terceras Jornadas de Patrimonio Arqueológico de la Comunidad de Madrid. Madrid, 210-222.

Mena, P.; Fernando, F.; Gras, R. (1988): La ciudad de Fosos de Bayona (Huete-Cuenca): datos de las dos últimas campañas de excavación. I Congreso de Historia de Castilla-La Mancha, Vol. 4, 1988, Toledo, 183-190.

Morín, J.; Urbina, D. (Eds.) (2013): El yacimiento de la Segunda Edad del Hierro del cerro de La Gavia (Villa de Vallecas, Madrid). Campañas 1999-2000. Madrid.

Morin, J. Urbina, D. (2012): Estudio de material cerámico en el yacimiento del cerro de La Gavia, Villa de Vallecas (Madrid). El Primer Milenio a.C. en la meseta central. De la longhouse al oppidum. Vol 2. Madrid, 203-223.

Morín, J.; Urbina, D.; Agustí, E.; Escolà, M.; López, F. J.; Pérez-Juez, A.; Barroso R. (2007): El cerro de La Gavia (Villa de Vallecas, Madrid capital). El urbanismo de un poblado de la II Edad del Hierro en la Comunidad de Madrid. Estudios sobre la Edad del Hierro en la Carpetania. Zona Arqueológica, 10, Vol II, 342-373.

Morín, J.; Urbina, D.; López, F.J.; Escolá, M.; Pérez-Juez, A. Agustí, E.; Barroso, R. (2012): El final de la Edad del Hierro. El habitat fortificado del Cerro de La Gavia. El Primer Milenio a.C. en la meseta central. De la longhouse al oppidum. Vol 2. Madrid. 2012, 62-119.

Pérez de Barradas, J. (1924): Introducción al estudio de la prehistoria madrileña. Revista de la Biblioteca, Archivo y Museo. Año I, n. I. Madrid, p. 13-35.

- (1935): Notas prehistóricas". Actas y memorias de la Sociedad Española de Antropología, Etnografía y Prehistoria. Tomo XIII, pp. 219-228.

Prados, L.; Perea A.; Santos, J.A. (1998): El hábitat carpetano del cerro del Gollino (Corral de Almaguer, Toledo). Iberia: Revista de la Antigüedad, $\mathrm{n}^{\circ} 1,53-72$

Priego, M. ${ }^{a}$ C. (1980): El Cerro de la Gavia (Vallecas, Madrid). II Jornadas de Estudios sobre la Provincia de Madrid. Madrid, p. 93-112.

Quero, S. Pérez, A.; Morín, J.; Urbina, D. Coords. (2005): El Cerro de La Gavia. El Madrid que encontraron los romanos. Catálogo exposición Museo de San Isidro, Madrid.

Ruiz Zapatero, G.; Álvarez Sanchís, J.R. (1995): Las Cogotas: oppida and the Roots of Urbanism in the Spanish Meseta. En Social coplexity and the developpement of towna in Iberia: from the Cooper Age to the second century AD. Proceedings of the British Academy vol.86. London. pp. 209-236.

Ruiz Zapatero, G.; Märtens, G; Contreras, M.; Baquedano, E. (2012): Los últimos carpetanos. El oppidum de El Llano de la Horca (Santorcaz, Madrid). Catálogo exposición MAR. Alcalá de Henares.

Sanz, C.; Velasco, J. (eds.) (2003): Pintia. Un oppidum en los confines orientales de la región vaccea. Investigaciones arqueológicas Vacceas, Romanas y Visigodas (1999-2003). Valladolid.

Urbina, D. (2000): La Segunda Edad del Hierro en el Centro de la Península Ibérica. Un estudio de Arqueología Espacial en la Mesa de Ocaña, Toledo, España. BAR International Series. 855 Oxford.

- (2012): Plaza de Moros y los recintos amurallados carpetanos. El Primer Milenio a.C. en la meseta central. De la longhouse al oppidum. Vol 2. Madrid. 36-61.

Urbina, D. García, O. Urquijo, C. (2004): "Plaza de Moros (Villatobas, Toledo) y los recintos amurallados de la II ${ }^{a}$ Edad del Hierro en el valle medio del Tajo". Trabajos de Prehistoria, 61, n 2, 155-166.

Valiente, S. (1987): Arqueología de la II Edad del Hierro. 130 años de arqueología madrileña. Madrid: Comunidad de Madrid, p. 121-133.

Vega, J.J.; Martín, M. P.; Pérez, D. (2009): El poblado de la Segunda Edad del Hierro del Cerro de la Fuente de la Mora (Leganés, Madrid). Actas de las Terceras Jornadas de Patrimonio Arqueológico de la Comunidad de Madrid, Madrid, 281-290. 